\title{
Monitoring Civic Project and Making Intelligent Decisions in Local Government using Geo-information System
}

\author{
Prerakkumar K. Doshi
}

\begin{abstract}
Geo-Information System today are being used worldwide to bring in streamline, efficient processes, to automate and present an integrated view of the Town. This integration view enables both management and maintenance of the Town infrastructure, as well as delivers effective governance and citizen services ${ }^{[1]}$ Monitoring Civic project in Local government using Geo-information system help in both drawing up strategies and allowing for critical and informed decision making in operational and emergent situation ${ }^{[1]}$ In this paper, various aspects of monitoring civic project in local government using Geo-information system are discussed along with implementation aspects. Paper also describes tracking civic project and how various departments allow the project branch to regulate the monitoring mechanism using smartphone. Approach in this paper is inclusive and considers the rendering of services blending enabling technologies to deliver good Governance and facilitate the citizen's interface with government. ${ }^{[2]}$
\end{abstract}

\section{Keywords}

Civic project, GIS, GPS, Government, Public service.

\section{INTRODUCTION}

Local government is spending a significant amount of its budget on augmenting urban infrastructure including various projects implementation such as Water Supply, Underground Drainage, Liquid Waste Management, Municipal Energy Efficiency, and Atal Mission for Rejuvenation and Urban Transformation (AMRUT), Road and Building Department etc. Local government has also focus on development of social infrastructure such as basic public amenities, education, health etc.

Local government believes in creating clean, green, livable and sustainable cities within a reasonable time-frame with due thrust on citizen participation. As of today, all the activities of citizen centric projects are managed and processed manually by the Project Implementation Unit (PIU)/Project Management Consultancy (PMC)/ Third Party Auditor (TPA). So there are change to duplication of works and partial/routine inspection focus is limited for Officers. In this regards, propose solution using Geo-information technology for effectively monitoring and management of project site inceptions.

Using Geo-information technology, organization can monitoring and management of regular site inspection reports and easily track down the progress of the mentioned project site. Also organization Head of the Department can make comments on any particular reports to have specific communication with concerned Officers about any issue.

\section{LITERATURE REVIEW}

A geographic information system; popularly known as GIS, is a computer-based tool for mapping and analyzing things that exist and events that happen on Earth. [3]

According to ESRI, USA ${ }^{[4]}$; GIS planning solutions can be used for

- Community-based design and planning

- Economic development of region

- Smart growth and improving the quality of life

- Creating livable communities

- Urban and regional planning

\subsection{Concept of Geo-information System}

Geo-information System is an integration following key components: hardware, software, data, people, and approaches. It answers two important questions what and where.

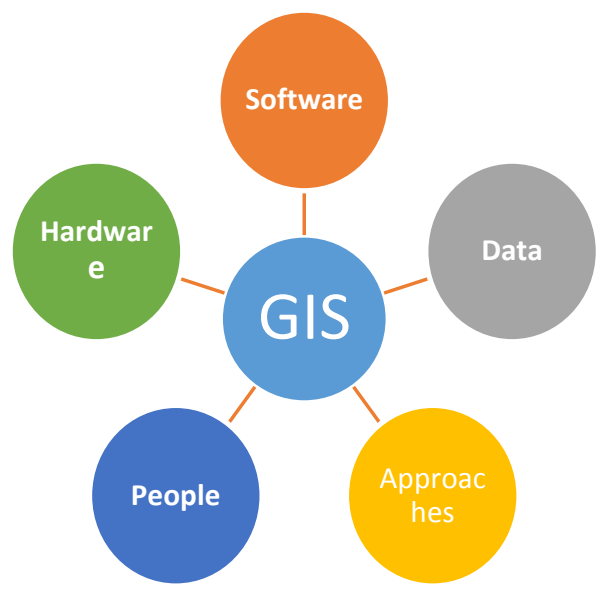

Fig.1: Components of Geo-information system

Hardware is the overall computer based system on which GIS operates.

Software components satisfy the functional requirements of the applications. Software component includes front end, back end application software and database management software.

Data is the important component of GIS which is used for generating useful reports as and when needed by various levels of operating authority.

Approaches are the formal processes set by organizations using GIS; and people include the GIS operators as well as end users.

\subsection{GIS Models}

GIS contains either an explicit geographic arrangement such as latitude and longitude or an implicit position such as an address of location/department/devices, postal code, census 
tract name, other identifier or some predefined name. Most of the GIS software basically follows following two models ${ }^{[3]}$.

- Vector models and

- Raster Models.

Also common tasks performed by most of the GIS based applications are as under:

- Input

- Manipulation

- Management

- Query and Analysis

- Visualization

\subsection{Security aspects in implementation}

As GIS is one of the network based applications, it is very important to maintain security of the data travelling through the network. Any networked based applications are susceptible to active or passive attacks; hence strong security related implementation is must for GIS based setup. To enhance the security of the system, various security mechanisms can be used ${ }^{[5]}$.

To enhance the security of system, various security and authentication techniques as mentioned $\mathrm{by}^{[6]}$ can be incorporated into GIS implementation.

\section{EXISTING SYSTEM}

Presently, all the activities of Citizen Centric project of local government are managed and processed manually by the PIU/PMC/TPA Site inspection Officers. Therefore, there are delays and high chances of duplication in the processing and sometimes get process in varied Offices. Also top authorities cannot track down the progress of the mentioned site of the projects due to unavailability of resources within time line. Moreover, there is no actual time information as to where site Officers are located on given working day.

\section{PROPOSED SYSTEM}

The rapid growth in Urbanization brings with it's an increased pressure on effectively management and monitoring of various projects under different government schemes running in Urban Local Bodies (ULBs). In this context and keeping in view the rapid technology changes, high demand from Government to digitalize the regular works. Many of the applications using Information and Communication Technologies (ICT) are already in place and use with different degree ${ }^{[2]}$ However, these are in most instances, dispersed and with limited Geo-information system components, restricted to use of maps for monitoring various project in the State. In this paper propose solutions using Geo-information technology as a unique and powerful technology for monitoring and management of site inspection of various project running in ULBs. Geo-Tagging Mobile application with Web Portal initiative finds relevance through eGovernance project in the organization for monitoring and management of various projects site inspection. The adoption of Geo-Information technologies within local government organization will increase the demand for sophisticated planning tools and techniques to assist in the complex implementation process. ${ }^{[8]}$ Local Government needs balance focus in terms of creating/upgrading civic infrastructure and leverage ICT and Geo-information system to improve efficiently and capacity of city service ${ }^{[9]}$

\section{CONCEPT OF PROPOSED SYSTEM}

Geo-information tag is the process of adding Geographical Information to various media in the form of metadata. The data usually consists of coordinates like latitude and longitude, but may even include bearing, altitude, distance and place names. Geo-information tag is most commonly used for photographs and can help public get a lot of specific information about where the picture was taken or the exact location of the site who logged on to a service. By Geoinformation tag photos, Officers of PIU/PMC/TPA can easily upload site visit photo of their locations on Map and administrator can monitor and manage the site visit records with various projects using their smartphone.

Geo-information tag is extremely useful to anyone who takes a large number of pictures and needs a way to record exactly where each photo was taken. By default, the camera application on smartphone has the ability to add GPS coordinates to the image file. In order to capture GPS data at the time the photograph is captured, the PIU/PMC/TPA must have a camera with built in GPS along with internet data service. Most smart phones already use a GPS chip along with build in camera to allow users to automatically GeoTag photos.

The Web based application allows to administrator to visualize the Goe-Taged site visiting photo which was uploaded by Officers of PIU/PMC/TPA. Different reports such as data wise search of sector wise that has been GeoTagged and their stages, reports regarding site visit not being tagged as yet.

The objective of Geo-Tagging is to track process of various projects running in ULBs. This Project is to manage knowledge in a fully integrated way - incorporating the widest possible range of information, protocols and procedures; changing and improving the model that governs interaction between the administration and Stakeholders, and making it more user-friendly for all concerned. Key objective of this concept are as follows:

- Improve the quality of Service Delivery System and offer these services with optimal effectiveness and transparency.

- Facilitate the decision making process of management by furnishing the right information at right time.

- Harness the use of technology to create sense of achievement amongst employees and citizens.

\section{HOW GEOTAGGING WORKS}

Step-1 Take photo of project site using Geo-Tagging App.

Step-2 Upload project site visit photo on Web based portal

Step-3 View site visit photo on Web based portal for review project progress. 

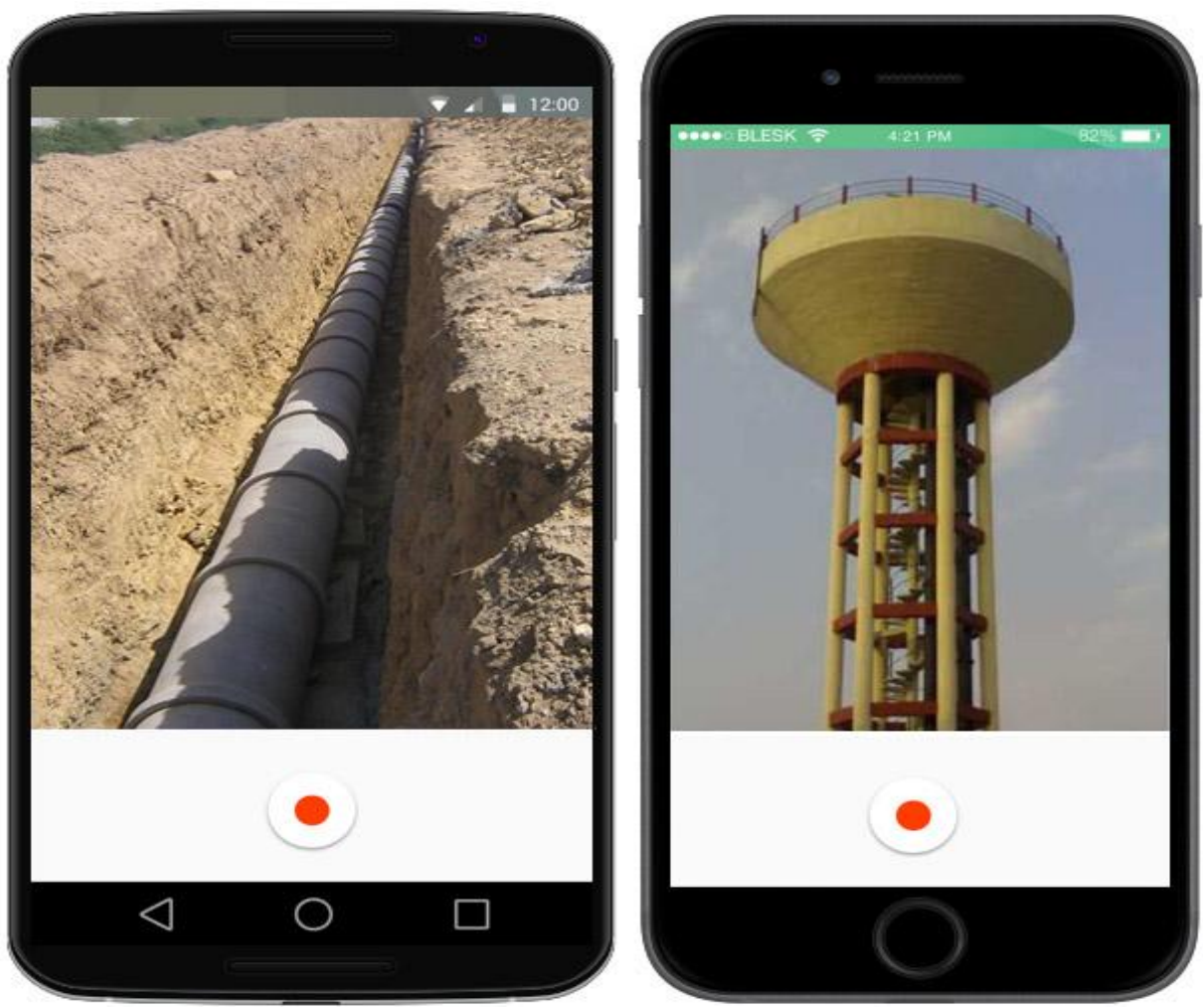

Fig.2 ${ }^{[7]}$ Take photo of project site using Geo-Tagging App.
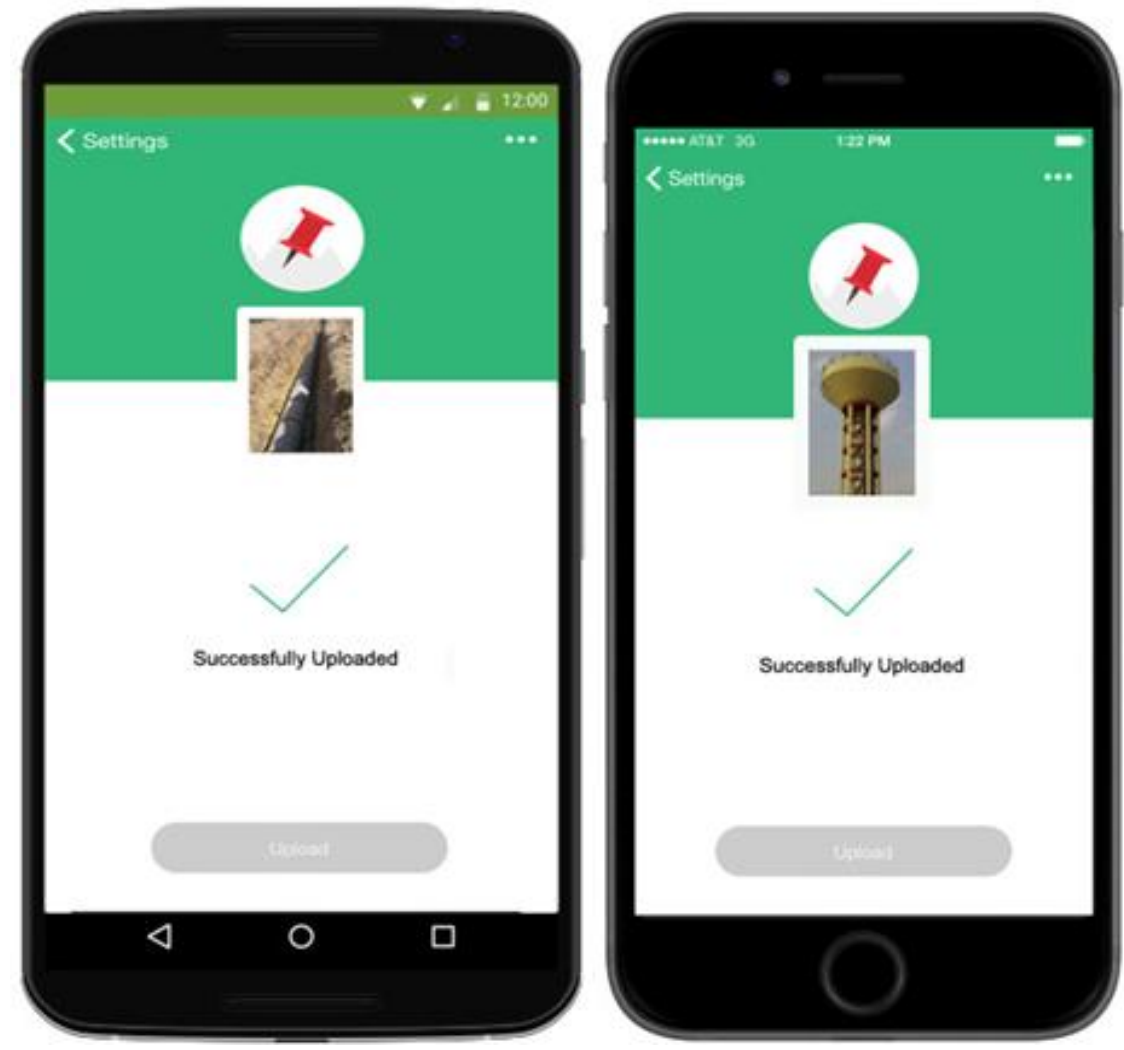

Fig. ${ }^{[7]}$ Upload project site photo on Web-portal. 


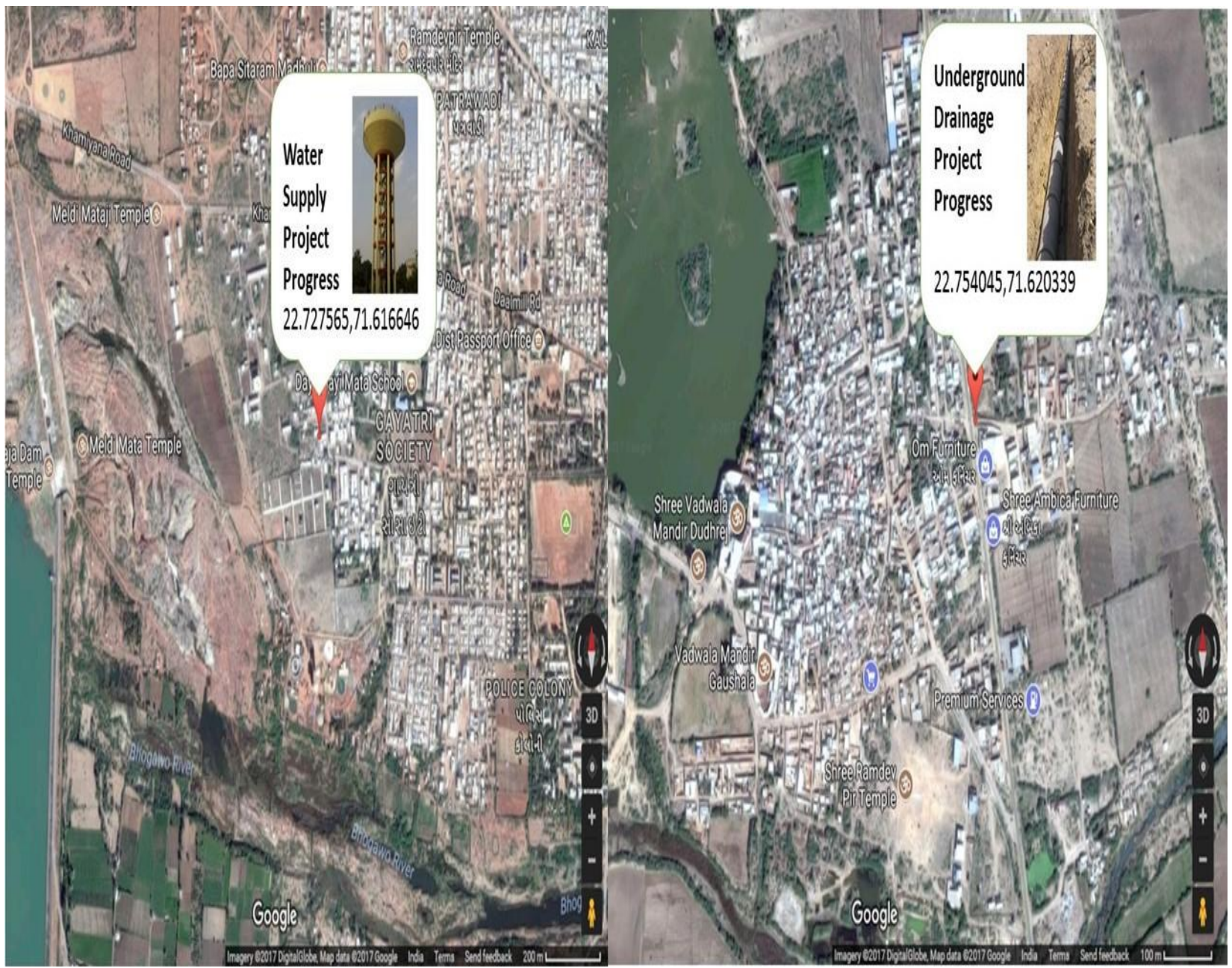

Fig.4 Tracking project progress using Geo- information portal

\section{BENEFITS TO LOCAL GOVERNMENT AND CITIZEN}

- Geo system helps local government to reduce and remove duplication of work.

- Information can be made available to the civic using information portal or KIOSK in project location.

- Accurate, and current information instantly saves local government works from having to waste time searching and tracking project progress.

- Civic project progress with GIS mapping can be easily accessed and shared with different department and Citizen.

- Improve citizen involvement in local Government and actively participation in process.

\section{CONCLUSION}

Local Government is expenses a significant amount of its budget on implementation of infrastructural civic project by monitoring all activities manually or partially using Geography information and not potential usage of Geography information. In this study, the literature was reviewed regarding GIS usage and Geography information studies to construct a new Geo-information system that is focused on tracking down various infrastructural civic project.

Geo-information system under e-Governance initiative is having an online Geography portal, which caters more to delivering its citizens centric and cost saving solutions for local government. Geo-information System on the other hand, is a technology which the potential to change mainstream local government burdens. Geo-data is a type of information used in Geography which combination of geo and graph and generate maps for better recognition of civic project tracking. Geo-tagging solution is not only use for tracking progress of project, but it use for local government as tools for decision maker and improve productivity. Department allows the project branch to regulate the monitoring mechanism through Smartphone device and reduce requirement of field working staff using Geo enable smartphone. Geo-information portal to provide effective solution for local government and citizen for specific access of town project status.

Tracking System allows the local government to manage and track the work hours at base and remote locations or job sites and inspection of site. The solution is a highly reliable, and easy-to-use that eliminates errors and deceptions and need of paperwork. Geo-information system provide wide variety of 
government functions and provide the opportunity to minimize project operational costs and maximize the benefits of citizen.

In future work, Geography information system usage in tracking infrastructural project progress extend solution with base requirement to various department in local government like Health, Education, Industry and Mining etc. for monitoring and extensive use of resources in governance.

\section{REFERENCES}

[1] The Concept Paper on "Geospatially Enabled Urbaninfrastructure and Governance Information System" for 100 Smart Cities Mission from the Association of Geospatial Industries (p. 3)

[2] The Concept Paper on "Geospatially Enabled Urbaninfrastructure and Governance Information System" for 100 Smart Cities Mission from the Association of Geospatial Industries (p. 8)

[3] https://www.highpointnc.gov/DocumentCenter/View/190 0 , retrieved on 15th November 2017
[4] http://www.esri.com/library/brochures/pdfs/gis-sols-forurban-planning.pdf, retrieved on 20th November 2017

[5] Khimani, Bansi, and Kuntal Patel. "A novel model for security and data access for jointly accessing the cloud service." BIJIT - BVICAM's International Journal of Information Technology7.1 (2015): 841-844.

[6] Khimani, Bansi, and Kuntal Patel. "Analysis of Authentication Techniques Adopted by End Users in Real-Life Cloud Implementation." Proceedings of International Conference on ICT for Sustainable Development. Springer Singapore, 2016.

[7] http://www.geotagphotos.net/user-guide, retrieved on 15th November 2017

[8] Integrated ICT and Geospatial Technologies Framework for 100 Smart Cities Mission reports from National Association of Software \& Services Companies. (p. 9). 